\section{DEVELOPMENT OF ANTIFOULING POLYETHERSULFONE (PES)-NANO ZnO MEMBRANE FOR PRODUCED WATER TREATMENT}

Tutuk Djoko Kusworoa*, Nita Aryantia, Qudratunb, Via Dolorosa Tambunana, Natalia Rosa Simanjuntaka

aChemical Engineering Department, Faculty of Engineering, University of Diponegoro, Jl. Prof. Sudharto, Tembalang, Semarang, 50239, Indonesia

bNano Center Indonesia, JIn. Raya Serpong KO. Batan Lama, No. A-12 RT 010/006, Setu, Serpong, Tangerang Selatang, 15310, Indonesia
Article history

Received

21 October 2017

Received in revised form

30 December 2017

Accepted

1 March 2018

Published online

16 May 2018

*Corresponding author tdkusworo@che.undip.ac.id

\section{Graphical abstract}

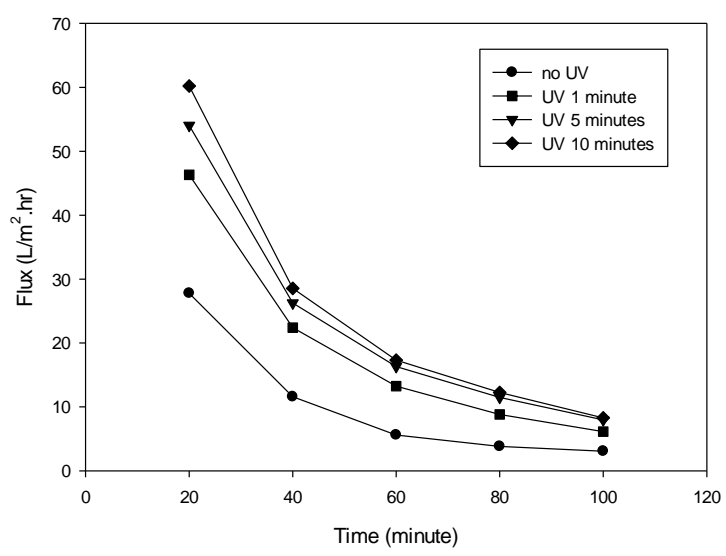

\begin{abstract}
Produced water is the side product of the oil and gas processing. This water is different from any common water because it contains the dangerous chemical substances and matters in the oil and gas. The usage of produced water and unprocessed waste of produced water contains a lot of dangerous substances that can endanger the environmental stability. The right processing is all that it needs to make produced water that is drinkable or usable. The membrane technology is one of the alternative waste water treatment technologies. But, as in the usage, it still lacks in the field of fouling and cannot fulfilled the specification of usable water. Thus, this becomes the reason that bases this research. In this paper, there will be made a polyethersulfone membrane with an inversion phase method and an addition of Nanoantifouling compound, $\mathrm{ZnO}$. The experimental results show that the TDS value of produced water decreased from 6600 into $1500 \mathrm{mg} / \mathrm{L}$. Nano $\mathrm{ZnO}$ addition of $1.5 \mathrm{wt}$-\% increase the permeate flux from 28 to 43 $\mathrm{L} / \mathrm{m}^{2}$.hr. The UV irradiation on the membrane increase the initial flux from 28 to $48 \mathrm{~L} / \mathrm{m}^{2}$.hr and also increase the TDS rejection from 16 to $25 \%$. This shows that by using Polyethersulfone (PES)-ZnO membrane, we can increase the separation performance. Hence, this method is suitable for processing the produced water into usable water.
\end{abstract}

Keywords: Double stages, Nano hybrid Membrane, Produced water, Polyethersulfone, Surface Modification, ZnO 


\subsection{INTRODUCTION}

The oil and gas industries take a big part in the Indonesian economics. A big exploration is needed to fulfilled the high-used of energy from oil and gas. Besides crude oil, during the exploration also has a produced water as its side product. Produced water will blow up in to the surface of the land. Produced water is by far the largest volume by product stream associated with oil and gas exploration and production. This water is different from any common water because it contains the dangerous chemical substances and matters in the oil and gas. The usage of produced water and unprocessed waste of produced water contains a lot of dangerous substances that can endanger the environmental stability. Produced water contains 1,2-200 mg/L of oil, for Total Dissolved Solid is 1000-15.000 mg/L, COD 20$2250 \mathrm{mg} / \mathrm{L}$ and TSS around 5-4200 mg/L [1].

All of the concentration that consist in produced water is bigger than the standard quality that already set in the Minister of Environment Regulation no. 19 of 2010 on the quality standard of waste water for oil and gas and geothermal business and activities as shown in Table 1.

Table 1 Quality standard of waste water for oil and gas and geothermal business and activities

\begin{tabular}{clll}
\hline No & \multicolumn{1}{c}{ Type } & Parameter & $\begin{array}{l}\text { Maximum } \\
\text { Conditions }\end{array}$ \\
\hline $1 \quad \begin{array}{l}\text { Produced } \\
\text { water }\end{array}$ & COD & $200 \mathrm{mg} / \mathrm{L}$ \\
& Oil and fat & $25 \mathrm{mg} / \mathrm{L}$ \\
& Sulfide (as $\mathrm{H}_{2} \mathrm{~S}$ ) & $0.5 \mathrm{mg} / \mathrm{L}$ \\
& TDS & $4000 \mathrm{mg} / \mathrm{L}$ \\
& $\begin{array}{l}\text { Drainage } \\
\text { Produced } \\
\text { Water }\end{array}$ & Oil and fat & $15 \mathrm{mg} / \mathrm{L}$ \\
& & $\begin{array}{l}\text { Total Organic } \\
\text { Carbon }\end{array}$ & $110 \mathrm{mg} / \mathrm{L}$ \\
\hline
\end{tabular}

The right processing is all that it needs to make produced water that is drinkable or usable. Some methods already tried to make produced water become drinkable or usable, such as the pretreatment method: coaleser bed and filtration, and hydrocyclone. But most of that methods have some weakness such as a complex operation, costly and there is a slime that really matter to that methods [2]. Besides all that methods, there is a method that has developed, the membrane technology. The membrane technology is one of the water processing technologies with a nanofiltration method. membrane technology is a physical process for the separation of material mixtures in which the membranes function like a filter. The separated substances are neither thermally nor chemically nor biologically modified [3]. Usually, pressure is used as a driving force in water treatment process such as microfiltration (MF), Ultrafiltration (UF) and Nanofiltration (NF) and Reverse Osmosis (RO). The used of membrane technology is expected to make produced water to be a usable or drinkable water. Membrane Nanofiltration is used for produced water treatments, because it has 0.0001 microns for its sized of pores. Nevertheless, membrane technology also has some weakness, it is lack of fouling which underlies our research.

Produced water contains some organic and inorganic compounds that can endanger the environmental stability. This method is expected to reduce that contaminant in produced water, so it can discharge directly to the nearby lake or re-utilize as a new water source. This is the reason why some researches focusing on this produced water treatment by using membrane technology.

Some researchers have been done to find out the parameter that can increase the efficiency in the separation method using membrane. Kusworo et al. [4] have done a research about the effect of combination of UV and thermal annealing on PESnano silica membranes. It stated that the UV irradiation and thermal annealing can improve the performance of nanosilica-hyrid membrane, as evidenced by a higher permeability and selectivity value of the nanosilica hybrid membrane. But, this research didn't observe the effect of time in UV irradiation PES-nano silica membranes. Libing et al. [5] said that adding non-solvent can increase the porosity of membrane but its only can applied in membrane reverse osmosis, ultrafiltration. The effect of non-solvent for nanofiltration haven't been analysed yet. Therefore, a research about the effect of competition of membrane for knowing the performance of membrane nanofiltration. Kusworo et al. [6] also have done a research about membrane asymmetric cellulose acetate by analysing the effect of the difference in concentration of PEG (Polietilen Glycol). It shows that membrane asymmetric cellulose acetate has a low flux with high selectivity and still has a fouling on it.

Cathie Lee et al. [7] analyse the performance of membrane polysulfone (Psf) that mixed with nanoparticle $\mathrm{ZnO}$. The used of $\mathrm{ZnO}$ is to reduce the fouling from oleat acid. Leo et al., said that adding 2 wt\% nano-ZnO can reduce hydrophobicity from Psf and increase the water permeability. However, the size pores of membrane are bigger because of agglomeration from that nanoparticle.

Stefan Balta et al. [8] in their research siad that hen nano-ZnO mixed with PES (Polyethersulfone), the flux of membrane is increasing and the permeability is higher. The other research that have done by Shen et al. [9] by using Bobine Serum Albumin(BSA) as a protein foulant in membrane PES-ZnO. Shen et al., stated that there are no differences in ratio BSA rejection. This is shows that $\mathrm{ZnO}$ doesn't have any effect to the size pore membrane PES-ZnO.

Therefore, in this research, the used of nano-ZnO is expected to reduce the agglomeration between the 
organic and inorganic compounds in mixed matrix membrane (MMM). And also by using PES-nano ZnO for produced water treatment, fouling on the membrane can be reduced. Besides that, ultraviolet will be used to remove the interface between polymeric and inorganic membrane. So, produced water can have fulfilled the specification of usable water after using membrane separation.

\subsection{METHODOLOGY}

\subsection{Materials}

Polyethersulfone (PES) and 1-methyl-2-pyrrolidone (NMP) were purchased from Merck. 1-methyl-2pyrrolidone (NMP) was used as the polymer solvent. ZnO nanoparticle was obtained from Center Indonesia.

\subsection{Membranes Preparation}

Nano ZnO Membrane was fabricated using phase inversion method. This nanofiltration membrane was made by 20 wt \% Polyethersulfone (PES), 1-methyl-2pyrrolidone (NMP) as solvent, and nano $\mathrm{ZnO}$ as nano particle with variable concentration of $0.5 \mathrm{w} t \%, 1 \mathrm{w} t$ $\%$, and $1.5 \mathrm{w}$ t\%. Polyethersulfone (PES), 1-methyl-2pyrrolidone (NMP), and nano $\mathrm{ZnO}$ that have been dissolved, stirred by magnetic stirrer at 400 rpm until homogenous. The homogenous membrane placed for 1 hour to remove the bubbles. After all the bubbles disappear, membranes were casted on glass plates using casting knife. Membrane gets UV treatment with time variation $(1,5$, and $10 \mathrm{~min})$. The membrane is stored in water for 1 day to sure that the solvent was disappear. Finally, the membrane was dried for 1 day at room temperature. The final membrane was ready to have a post-treated and ready to use for produced water treatment.

\subsection{Characterization of Nano ZnO Membrane}

Membrane used in produced water treatment using a dead-end filtration system and the value of flux determined by the tool. In dead-end filtration is placed a membrane to be measured permeability. Membrane was pressured at 5 bar for $5 \mathrm{~min}$ to compact them before the permeate accommodated for 20 minutes in 5 dots. Membrane permeability was calculated by equation (1) as follow:

$J=\frac{V}{A \cdot t}$

where, $\mathrm{J}$ is permeate flux $\left(\mathrm{L} \cdot \mathrm{m}^{-2} \cdot \mathrm{hr}^{-1}\right), \mathrm{A}$ is membrane surface area $\left(\mathrm{m}^{2}\right), t$ is operating time $(\mathrm{h}), \mathrm{V}$ is volume of permeate $(\mathrm{L})$.

Determination of rejection membranes can be seen from the concentration of turbidity, salinity, and total dissolved solid (TDS) before and after passing through the membrane. The analysis turbidity can be calculated using turbidity meter, salinity with titration and TDS with TDS meter. Rejection of Membrane was evaluated by equation (2) as follow:

$R=\left(1-\frac{C_{p}}{C_{f}}\right)$

where, $R$ is rejection efficiency, $C_{p}$ is solute concentration in permeate, $C_{f}$ is solute concentration in feed.

Morphologies of membrane can be observed with Scanning Electron Microscopy (SEM). SEM is a simple method for characterizing and looking the pore of a membrane (surface). SEM shows that indeed membrane nanofiltration with pore size less than $2 \mathrm{~nm}$.

The schematic of dead-end filtration is shown at Figure 1.

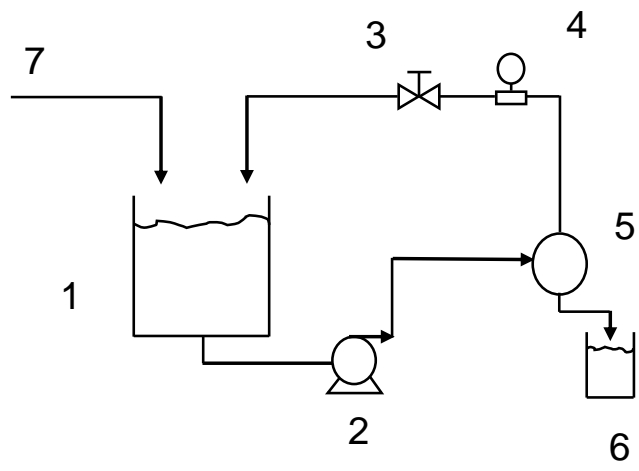

1. Feed Tank

2. Water Pump

3. Recycle Valve

4. Pressure Gauge

5. Membrane Filter

6. Permeate Tank

7. Produced Water

Figure 1 Schematic flow diagram of Dead-end filtration membrane system

\subsection{RESULTS AND DISCUSSION}

\subsection{Effect of ZnO Concentration on the Membrane Performance}

To observe the effect of the nanoznO addition, the membrane was fabricated with various nano-ZnO loading ranging from 0.5 to $1.5 \mathrm{w}+\%$. Then the membrane is used to treat produced water to evaluate the flux and rejection. Membrane flux measurement is using dead-end filtration, where flux membrane is the ratio of permeate, surface area, time and pressure. The results of flux measurement by the different concentration of $\mathrm{ZnO}$ shown at Figure 2 


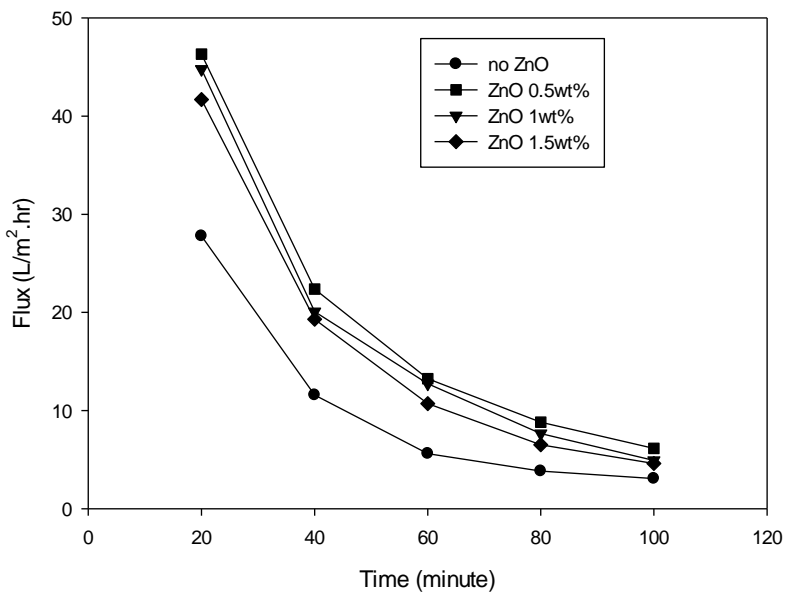

Figure 2 Effect of Concentration ZnO to Flux

In this study, the performance of nano hybrid PES$\mathrm{ZnO}$ and PES membrane in produced water treatment was compared. Figure 2 Shows the differences of performance between PES(Polyethersulfone) and PES-nanoZnO membrane. PES-nanoZno has the higher flux than PES membrane. When $\mathrm{ZnO}$ as nanoparticle is added into PES membrane, it can increase the hydrophilicity of its membrane [8]. Hydrophilicity is Hydrophilicity (also called hydrophilic) is a characteristic of materials exhibiting an affinity for water. Hydrophilic literally means "water-loving" and such materials readily adsorb water. Hydrophilic materials have high surface tension values. The surface chemistry allows these materials to be wetted forming a water film or coating on their surface. Therefore, if membrane has this properties, it is more easily to penetrate or pass through membrane pores This is what causes water to diffuse faster in membrane PES-nanoZnO. Thus, the increasing flux occurred when $\mathrm{ZnO}$ is added.

However, Figure 2 also shows that the more concentration of $\mathrm{ZnO}$ is added, the flux number of this membrane even has a decreasing. The higher concentration is added, the aggregation also occurred. The aggregation of $\mathrm{ZnO}$ causing a clogging on the pores of membrane and will decreasing the flux number of it. This result corresponds with previous research performed by Kusworo et al. [10]. It was stated in the research that the nano-ZnO formed an aggregation to form nanodomain on the membrane surface. This nano domain induced the high permeability due to a void fraction (nano-gaps) among the nano particles in the domain. Nano-ZnO has a stronger hydrophilic characteristic and hence it could not perfectly attach to PES matrix due to the hydrophobicity of PES molecules.

Besides, the flux number, the performance of membrane also analyzed by its rejection. Membrane rejection is analyzed by concentration of $\mathrm{S}^{2-}$ and total dissolved solid (TDS) of produced water. The results of rejection with different concentration of $\mathrm{ZnO}$ is shown at Figure 2 and Figure 3.

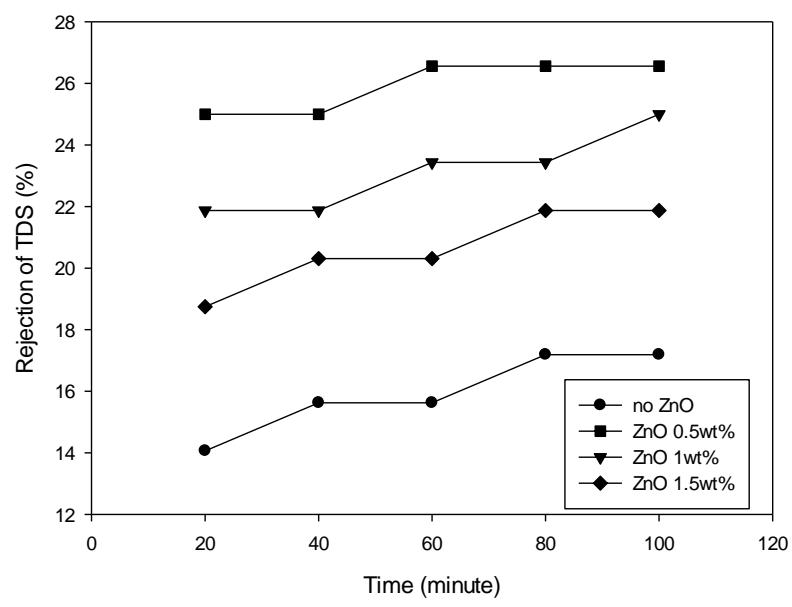

Figure 3 Effect of Concentration ZnO to TDS Rejection

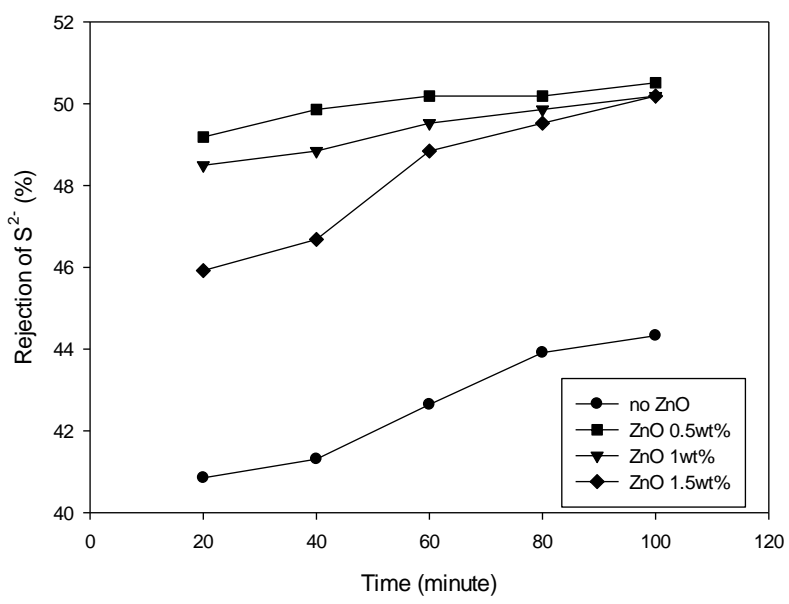

Figure 4 Effect of Concentration $\mathrm{ZnO}$ to $\mathrm{S}^{2-}$ Rejection

Figure 3 and Figure 4 show that the higher concentration of $\mathrm{ZnO}$, so do the rejection. The more concentration of $\mathrm{ZnO}$ is added causes the high of viscosity from the film casting and make the membrane surface has a smaller pore that can increasing the rejection of membrane. As reported by previous researchers $[12,13]$, the addition of nano materials will provide molecular sieve mechanism, it will enhance the solute rejection of the membrane.

\subsection{Effect of UV Irradation on the Membrane Performance}

Besides modification of concentration $\mathrm{ZnO}$, UV irradiation is also given to analyzed the performance of membrane with time of irradiation as its variables (1,5,10 minutes). Membrane flux can determine by using dead-end filtration. The results of rejection with 
different time of UV(Ultraviolet) irradiation shown at Figure 5.

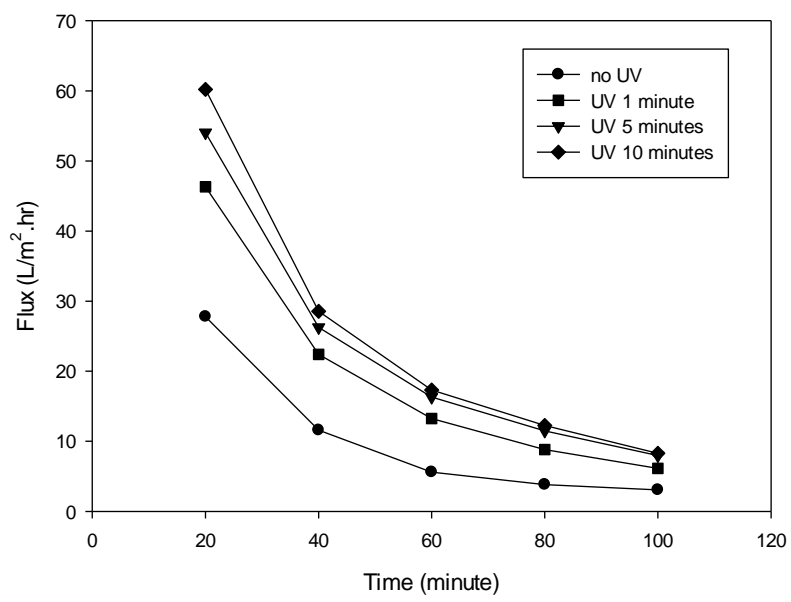

Figure 5 Effect of UV Irradation Time to Flux

Figure 5 shows that the longer the UV irradiation, the flux value increases. Polyethersulfone (PES) with UV irradiation has a higher flux value than PES without UV-irradiation. This phenomenon is caused by the effects of UV light exposed to the polymer membrane. The UV light-induced the polymer chains to restructure and grafting so that the polymer becomes denser. While the longer exposure of UV light on the membrane surface, it leads to the polymer chain degradation of polyethersulfone polymer. As the consequences, the membrane pores will be larger and the UV treatment increases the hydrophilicity of PES membrane as well as increases the flux [13]. The similar result also has been reported by Konruang et al. [14] where PES membrane becomes more hydrophilic after exposing under UV lights. There will be a maximum limit of the duration of UV irradiation, so the longer the irradiation will not always make the flux value become higher. Since the longer UV irradiation can also lead to crosslinking, it should be found the optimum UV irradiation duration [15].

Beside from the flux value, the value of rejection was also observed. The results of rejection measurements with variable duration of UV irradiation can be observed in Figure 6 and 7.

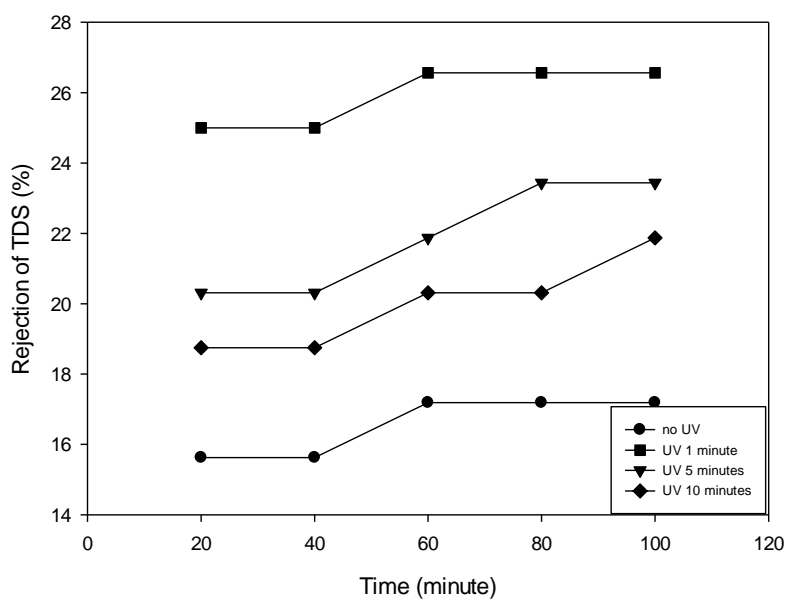

Figure 6 Effect of UV Irradation Time To TDS Rejection

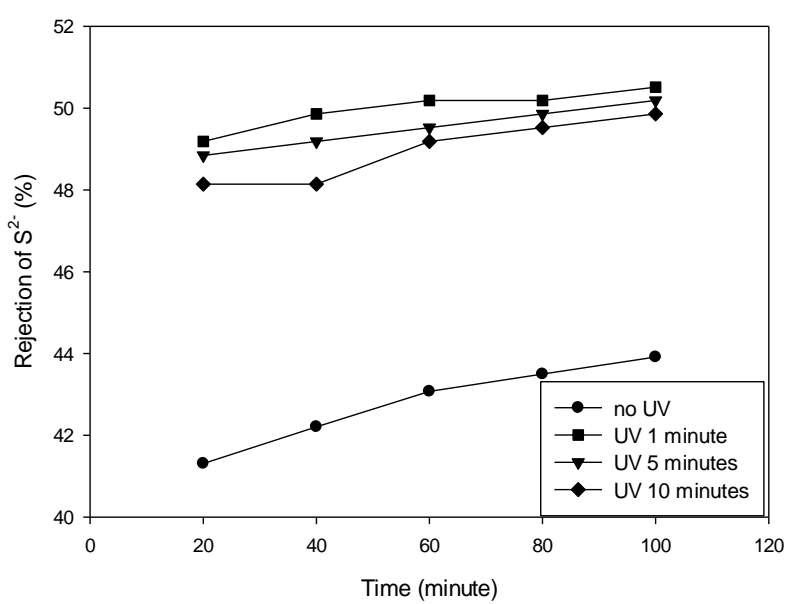

Figure 7 Effect of UV Irradation Time To S2- Rejection

In Figure 6 and 7 it can be seen that the longer the UV irradiation, the rejection value of the membrane will decrease. This is because the pores of the membrane become larger, causing the membrane's ability to filter more easily and can passes the unwanted ions through its pores. This is what causes the rejection is increasing.

\subsection{Stability of Membrane}

Membrane performance is not only seen from the flux and rejection but also needs to analyzed the stability of the membrane. The membrane stability of the flux value can be seen in Figure 8. 


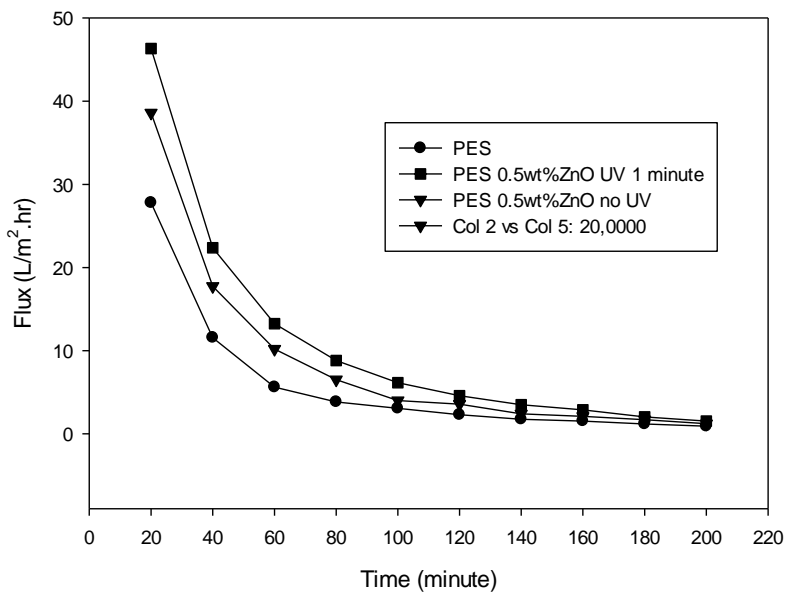

Figure 8 Stability of Membrane to Flux

In Figure 8 it can be seen that the longer the time, the flux value will decrease and the higher flux value is PES $0.5 \% \mathrm{ZnO}$ with UV. This proved that UV-treated membranes are more stable against fouling than those without UV. The decrease of flux over the duration of membrane use due to the accumulation of certain components on the membrane surface or commonly called fouling. From the graph its also can be seen that the addition of ZnO treatment and UV irradiation can increase the flux.

Apart from the flux value, the stability can also be seen from the value of the rejection. The membrane stability of the flux value can be seen in Figure 9 and 10.

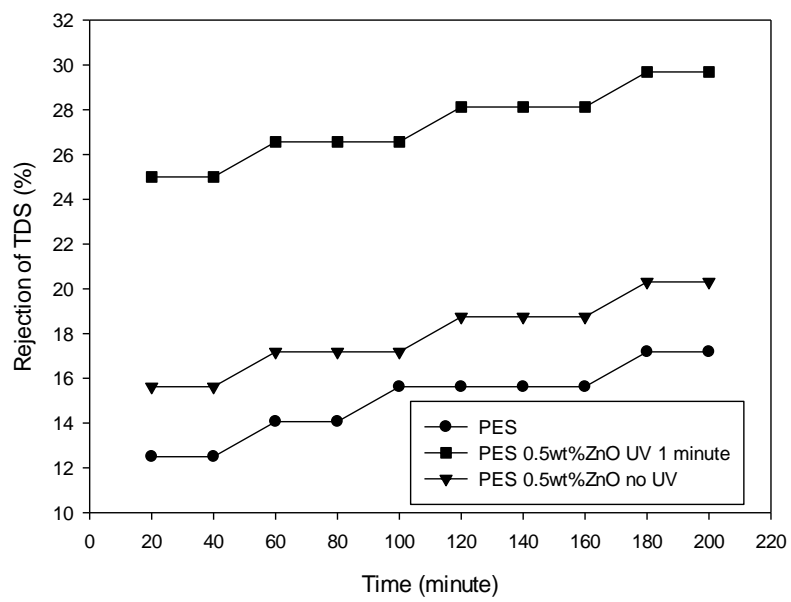

Figure 9 Stability of Membrane to TDS Rejection

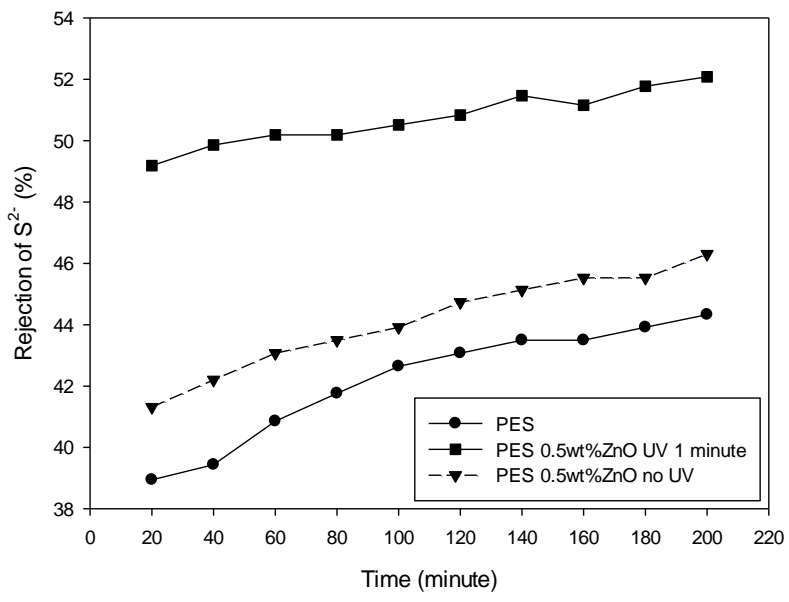

Figure 10 Stability of Membrane to S2- Rejection

In Figure 9 and 10 can be seen that the longer the time, the rejection time increases. This happens because the more fouling that is formed on the surface of the membrane makes membrane pores become smaller A denser and stable pore structure will increase the rejection of the membrane. This graph also shows by adding ZnO and UV irradiation has higher rejection. This is because the addition of ZnO and UV irradiation can make the membrane structure denser.

\subsection{CONCLUSION}

The results from this study show that a PES-ZnO matrix membrane with particles was fabricated by the combination of solution blending and phase inversion method and this membrane is used for produced water treatment. With the addition of nanO-ZnO particles, fouling on the surface membrane is decreasing. PES-nano $\mathrm{ZnO}$ has the higher flux and rejection value than PES without nano ZnO. Flux value is also increase as UV irradiance is up and UV-irradiated polyethersulfone (PES) is higher in flux value than non-UV irradiated. This is caused by chain cutting (chain scission process) and crosslinking process. PES-nano ZnO with UV irradiation has the best stability than PES without nano $\mathrm{ZnO}$ and UV irradiation.

\section{Acknowledgement}

The authors would thank to Waste treatment laboratory of Chemical Engineering Department UNDIP for supporting facilities. Nano Center Indonesia as research partner which supplied the nanomaterials. 


\section{References}

[1] Alzahrani, S., \& Wahab, A. 2014. Challenges \& Trends in Membrane Technology Implementation for Produced Water Treatment: A Review. Journal of Water Process Engineering. 4: 107-133. DOI: 10.1016/j.jwpe.2014.09.007.

[2] Motta, A., Borges, C., Esquerre, K., \& Kiperstok, A. 2014. Oil Produced Water treatment for oil Removal by an Integration of Coalescer Bed and Micro Filtration Membrane Processes. Journal of Membrane Science. 469: 371-378. DOI: 10.1016/j.memsci.2014.06.051.

[3] Pinnekamp, J., \& Friedrich, H. (Eds.). 2006. Membrane technology For Waste Water Treatment. FiW Verlag.

[4] Kusworo, T. D., Utomo, D. P., Aryanti, N., \& Qudratun. 2017. Synergistic Effect of UV Irradiation and Thermal Annealing to Develop High Performance Polyethersulfone-nano Silica Membrane for Produced Water Treatment. Journal of Environmental Chemical Engineering. 5(4): 3290-3301. DOI: 10.1016/j.jece.2017.06.035.

[5] Libing Zheng, Z. Wu, Yong Zhang, Yuansong Wel, Jun Wang. 2016. Effect of Non-solvent Additives on the Morphology, Pore Structure, and Direct Contact Membrane Distillation Performance of PVDF-CTFE Hydrophobic Membranes. Journal of Environmental Sciences. 45: 28-39. DOI: 10.1016/j.jes.2015.09.023.

[6] Kusworo, T. D., Budiyono, Supriyadi, and Hakika. 2014. Enhanced Separation Performance of Cellulose Acetate Membrane for Brackish Water Separation Using Modification of Additives and Thermal Annealing, International Journal of Waste Resource. 4: DOl: 10.4172/2252-5211.1000131

[7] C. P. Leo, W. P. Cathie Lee, A. L. Ahmad, A. W. Mohammad. 2012. Polysulfone Membranes Blended with ZnO Nanoparticles for Reducing Fouling by Oleic Acid. Separation and Purification Technology. 89: 51-56. DOI: 10.1016/j.seppur.2012.01.002.

[8] S. Balta, A. Sotto, P. Luis, L. Benea, B. Van der Bruggen, J. Kim. 2012. A New Outlook on Membrane Enhancement with Nanoparticles: The Alternative of $\mathrm{ZnO}$. Journal of
Membrane Sciece. 389: 155-161. DOI: 10.1016/j.memsci.2011.10.025.

[9] Shen, L., Bian, X., Lu, X., Shi, L., Liu, Z., Chen, L., \& Fan, K. 2012. Preparation and Characterization of ZnO/polyethersulfone (PES) Hybrid Membranes. Desalination. 293: 21-29. DOI: 10.1016/j.desal.2012.02.019.

[10] Kusworo, T. D., Ismail, Aryanti, N., Widayata, Qudratun, \& Utomo, D. P. 2017. Enhanced Anti-Fouling Behavior and Performances of Nano Hybrid Pes-SiO ${ }_{2}$ and Pes-ZnO Membranes for Produced Water Treatment. Jurnal Teknologi (Sciences \& Engineering). 79(6): 129-140. DOI: 10.1111./jt.v79.10692.

[11] Alhoshan, M., Alam, J., Dass, L. A., \& Al-Homaidi, N. 2013. Fabrication of Polysulfone/ZnO Membrane: Influence of ZnO Nanoparticles on Membrane Characteristics. Advances in Polymer Technology. 32(4): 21369(1)-(7). DOI: 10.1002/adv.21369

[12] Zhao, S., Yan, W., Shi, M., Wang, Z., Wang, J., \& Wang, S. 2015. Improving Permeability and Antifouling Performance of Polyethersulfone Ultrafiltration Membrane by Incorporation of ZnO-DMF Dispersion Containing Nano$\mathrm{ZnO}$ and Polyvinylpyrrolidone. Journal of Membrane Science. 478: 105-1 16. DOI: 10.1016/j.memsci.2014.12.050.

[13] Homayoonfal, M., Akbari, A., \& Mehrnia, M. R. 2010. Preparation of Polysulfone Nanofiltration Membranes by UV-Assisted Grafting Polymerization for Water Softening. Desalination. 263(1): 217-225. DOl: 10.1016/j.desal.2010.06.062

[14] Konruang, S., Sirijarukul, S., Wanichapichart, P., Yu, L., \& Chittrakarn, T. 2015. Ultraviolet-ray Treatment of Polysulfone Membranes on the $\mathrm{O}_{2} / \mathrm{N}_{2}$ and $\mathrm{CO}_{2} / \mathrm{CH}_{4}$ Separation Performance. Journal of Applied Polymer Science. 132(25): 42074(1)-(8). DOI: 10.1002/app.42074.

[15] Pieracci, J., Crivello, J. V., \& Belfort, G. 2002. Increasing Membrane Permeability of UV-modified Poly(ether sulfone) Ultrafiltration Membranes. Journal of Membrane Science. 202(1-2): 1-16. DOI: 10.1016/S0376-7388(01)00624- 